\title{
The Relationship between Repetitive Behaviors and Growth Hormone Response to Sumatriptan Challenge in Adult Autistic Disorder
}

\author{
Eric Hollander, M.D., Sherie Novotny, M.D., Andrea Allen, Ph.D., Bonnie Aronowitz, Ph.D., \\ Charles Cartwright, M.D., and Concetta DeCaria, Ph.D.
}

Autism is heterogeneous with respect to clinical symptoms
and etiology. To sort out this heterogeneity in autism, we
investigated whether specific neurobiological markers vary
in parallel to core symptomatology. Specifically, we
assessed growth hormone response to the 5-HT 1d agonist,
sumatriptan, and linked this measure of serotonergic
function to the severity of repetitive behaviors in adult
autistic patients. Eleven adult patients with autism or
Asperger's disorder were randomized to single dose
sumatriptan (6 mg SQ) and placebo challenges, separated
by a one-week interval. In adult autistic disorders, severity of repetitive behaviors at baseline, as measured by YBOCScompulsion score, significantly positively correlated with both peak delta growth hormone response and area under the curve growth hormone response to sumatriptan. Thus, the severity of a specific behavioral dimension in autism (repetitive behaviors) parallels the sensitivity of the 5-HT $1 d$ receptor, as manifest by sumatriptan elicited $G H$ response. [Neuropsychopharmacology 22:163-167, 2000] (C) 1999 American College of Neuropsychopharmacology. Published by Elsevier Science Inc.
KEY WORDS: Autism; Asperger's disorder; Serotonin; Sumatriptan; Growth hormone; Repetitive behavior

Autism is heterogeneous with respect to clinical symptoms and etiology. To sort out this heterogeneity in autism, one might determine whether specific neurobiological markers vary in parallel to key clinical symptoms. Autism is characterized by three unique behavioral dimensions: social impairment, communication difficulties and rigid, restricted interests, and repetitive behaviors. One recent study explored the relationship between repet-

From the Seaver Autism Research Center and the Department of Psychiatry, Mt. Sinai School of Medicine, New York, NY.

Address correspondence to: Eric Hollander, M.D., Seaver Autism Research Center, Department of Psychiatry, Box 1230 Mt. Sinai School of Medicine, One Gustave L. Levy Place, New York, NY 10029.

Received January 15, 1999; revised May 3, 1999; accepted September 10, 1999 . itive behaviors in autism and D8/17, a B-lymphocyte antigen marker expressed at increased levels in patients with rheumatic fever, as well as in patients with neuropsychiatric disorders characterized by repetitive behaviors such as Sydenham's chorea, Tourette's syndrome and obsessivecompulsive disorder. Of interest, obsessive compulsive disorder (OCD) occurs with increased frequency in first degree relatives of autistic patients and is associated with the broader phenotype of autism (Bolton et al. 1998). D8/17 expression was found to be significantly positively correlated with the severity of repetitive behaviors as measured by the Yale-Brown Obsessive Compulsive Scale - compulsivity subscale in childhood and adolescent autism (Hollander et al. 1999). We have hypothesized that repetitive behaviors in autism may also be related to serotonergic (5-HT) dysfunction (Hollander et al. 1998).

Pharmacological treatment studies support a role of 5-HT in autistic disorders. Double-blind studies of the 
serotonin reuptake inhibitors (SRI's) clomipramine (Gordon et al. 1993), fluvoxamine (McDougle et al. 1996b), and fluoxetine (Hollander et al., unpublished data), as well as open label studies of fluoxetine (Mehlinger et al. 1990) and sertraline (Steingard et al. 1997) have documented efficacy in treating both global autistic symptoms as well as symptoms of repetitive behaviors and restricted interests in up to $60 \%$ of patients treated.

Several biological studies have also suggested 5-HT dysregulation in autistic patients, however the findings have not been uniform, but rather replicated in subgroups of patients. For example, contradictory results in linkage disequilibrium analyses of two common alleles (long and short) of the 5HT transporter (5HTT) gene have been reported. While there was linkage between the short allele and a narrowly defined group of autistic probands (Cook et al. 1997), an association between the long allele and a more broadly defined group of autistic probands has also been reported (Klauck et al. 1997).

Pharmacological challenge studies with 5-hydroxytryptophan and fenfluramine have demonstrated reduced prolactin response in some patients with autism (Hoshino et al. 1984; McBride et al. 1989), however age, gender, and racial/ethnic factors may account for some of the heterogeneity. Depletion of the 5-HT precursor, tryptophan, induced a worsening of autistic symptoms in some, but not all, patients (McDougle et al. 1996a). There is evidence for increased whole blood serotonin not only in patients with autism (Hoshino et al. 1984; Anderson et al. 1987), but also in their first degree relatives (Piven et al. 1991; Cook et al. 1994; Leboyer et al. 1999). Of interest, parents of autistic patients with increased whole blood serotonin scored higher on ratings of repetitive behavior than parents without elevated whole blood serotonin (Cook et al. 1994). This reinforces the notion of heterogeneity of 5HT function in autism as well as elucidating a possible link to repetitive behaviors.

PET studies with radiolabeled alpha methyl tryptophan in autistic children demonstrated evidence of decreased serotonin synthesis in frontal and thalamic regions but increased 5HT synthesis in the contralateral cerebellar dentate regions (Chugani et al. 1997). Of interest, the areas of decreased 5HT synthesis, such as the frontal cortex, are rich in 5HT 1d inhibitory autoreceptors (Pascual et al. 1996), whereas the brain regions with increased 5HT synthesis, such as the cerebellum, lack 5HT 1d inhibitory autoreceptors.

Sumatriptan, originally marketed as an anti-migraine medication, is primarily a 5-HT1d receptor agonist but may also bind to 5 -HT 1b, $1 \mathrm{f}$ and $1 \mathrm{a}$ receptors (Adham et al. 1997; Peroutka et al. 1989). The 5HT 1d receptor has both alpha and beta subtypes, however sumatriptan binds nonspecifically to both subtypes (Bard et al. 1996). Sumatriptan has been shown to increase growth hormone release in normal controls (Franceschini et al. 1994) via increased growth hormone releasing hormone (GHRH) which stimulates GH release, and inhibition of somatostatin which inhibits GH release (Yatham et al. 1997; Mota et al. 1995). Anecdotal case reports have suggested that sumatriptan improved symptoms of autism, as well as migraine headaches when taken by patients who suffer from both disorders. We previously demonstrated that autistic patients have increased growth hormone response to sumatriptan compared to matched controls (Novotny et al. 1999, in press). In this study, we examine the relationship between the severity of the repetitive behavior dimension and growth hormone response to sumatriptan in adult autistic patients.

\section{METHODS}

To evaluate the role of the 5-HT 1d receptor in autism, we utilized single dose challenges with sumatriptan (a primarily 5-HT 1d agonist) and placebo. Eleven adult patients (mean age $=31.2$ years, range $=18.5-53.2)$, $(10$ male, 1 female), diagnosed with autism $(n=7)$ or Asperger's disorder $(n=4)$ by both Autism Diagnostic Interview (Lord et al. 1994) and DSM IV criteria, participated in this study after patients and parents signed written informed consent. All patients were medically healthy, without a current or past history of schizophrenia, psychotic disorders, substance abuse, other Axis I mental disorders, or seizure disorders. Seven patients were medication free for greater than one year prior to the study; two patients were medication free for greater than seven weeks prior to the study, and the remaining two patients (one who was on fluvoxamine and risperidone, and one on clonazapam) were medication free for a minimum of two weeks prior to and throughout the study. Baseline severity of repetitive behaviors was assessed with the YBOCS compulsion subscale prior to entrance into the study.

The patients underwent two identical challenge days, separated by one week, with single dose sumatriptan or placebo. At 8:00 a.m., after an overnight fast, the patients reported to the Clinical Research Center where a catheter was inserted at 8:30 a.m. The patients received either sumatriptan, $6 \mathrm{mg} \mathrm{SQ}$, or placebo, at 9:30 a.m. Blood samples for growth hormone $(\mathrm{GH})$ were obtained starting thirty minutes prior to and at $0,60,90$, 120, and 240 minutes after drug administration. Blood pressure, pulse, and oral temperature were measured at 15 minute intervals. Side effects occurring during the procedure were recorded. To assess the relationship between core symptom components in autism and 5-HT function, we correlated baseline Y-BOCS-compulsion scores and ADI-R algorithm subscales for communication and social interaction with both peak delta GH and 
area under the curve GH using Spearman's correlations, given the small sample size and the absence of a normal distribution. To compare $\mathrm{GH}$ response to sumatriptan vs. placebo, data was analyzed by students' t-test, both paired and independent, with a twotailed significance of $p \leq .05$.

\section{RESULTS}

Neither age nor gender influenced growth hormone (GH) response to sumatriptan. Side effects to sumatriptan included lightheadedness, anxiety, headache and mild nausea and did not appear to relate to GH response. None of the patients experienced side effects on placebo.

Of special interest, the severity of repetitive behaviors, as measured by YBOCS-compulsion scores at baseline, significantly positively correlated with both peak delta GH response to sumatriptan $(\mathrm{r}=0.650, p=.042)$ and area under the curve $\mathrm{GH}$ response to sumatriptan $(\mathrm{r}=0.754, p=.012)$ (Figure 1a and 1b). However, neither the communication nor social interaction subscales of the ADI-R algorithm significantly correlated with peak delta $(\mathrm{r}=0.502, p=.168 ; \mathrm{r}=0.555, p=.074$, respectively) or area under the curve $(\mathrm{r}=0.494, p=.177$; $\mathrm{r}=0.622, p=.074$, respectively) $\mathrm{GH}$ response to sumatriptan. The peak delta GH response $(\mathrm{ng} / \mathrm{ml})$ to sumatriptan $(5.08 \pm 6.12)$, was significantly greater than for placebo $(1.11 \pm 1.39)(\mathrm{t}=2.30, \mathrm{df}=10 ; p=.04)$ and area under the curve GH response to sumatriptan $(21.22+31.53)$ was trend greater compared to placebo $(7.61+10.01)(\mathrm{t}=1.58, \mathrm{df}=10, p=.073)$.

\section{DISCUSSION}

Our results show that the severity of repetitive behaviors (as measured by the YBOCS-compulsion subscale), but not other behavioral dimensions (communication and social deficits as measured by ADI-R algorithm subscales), parallels sumatriptan-elicited growth hormone response. This suggests that a specific component of the 5HT system (the 5HT 1d receptor) may play a role in mediating one specific behavioral component of autistic disorder (repetitive behavior), thus influencing heterogeneity in autism. Of note, the ADI is generally not used as a scale for rating severity of social and communication problems, but rather for rating whether there has ever been abnormalities in these areas characteristic of autism. The Ritvo Freeman Real Life Rating Scale or the Childhood Autism Rating Scale might be useful for rating severity of these dimensions in future studies.

Since GH response to sumatriptan was found to be significantly greater than to placebo, it is, therefore, not
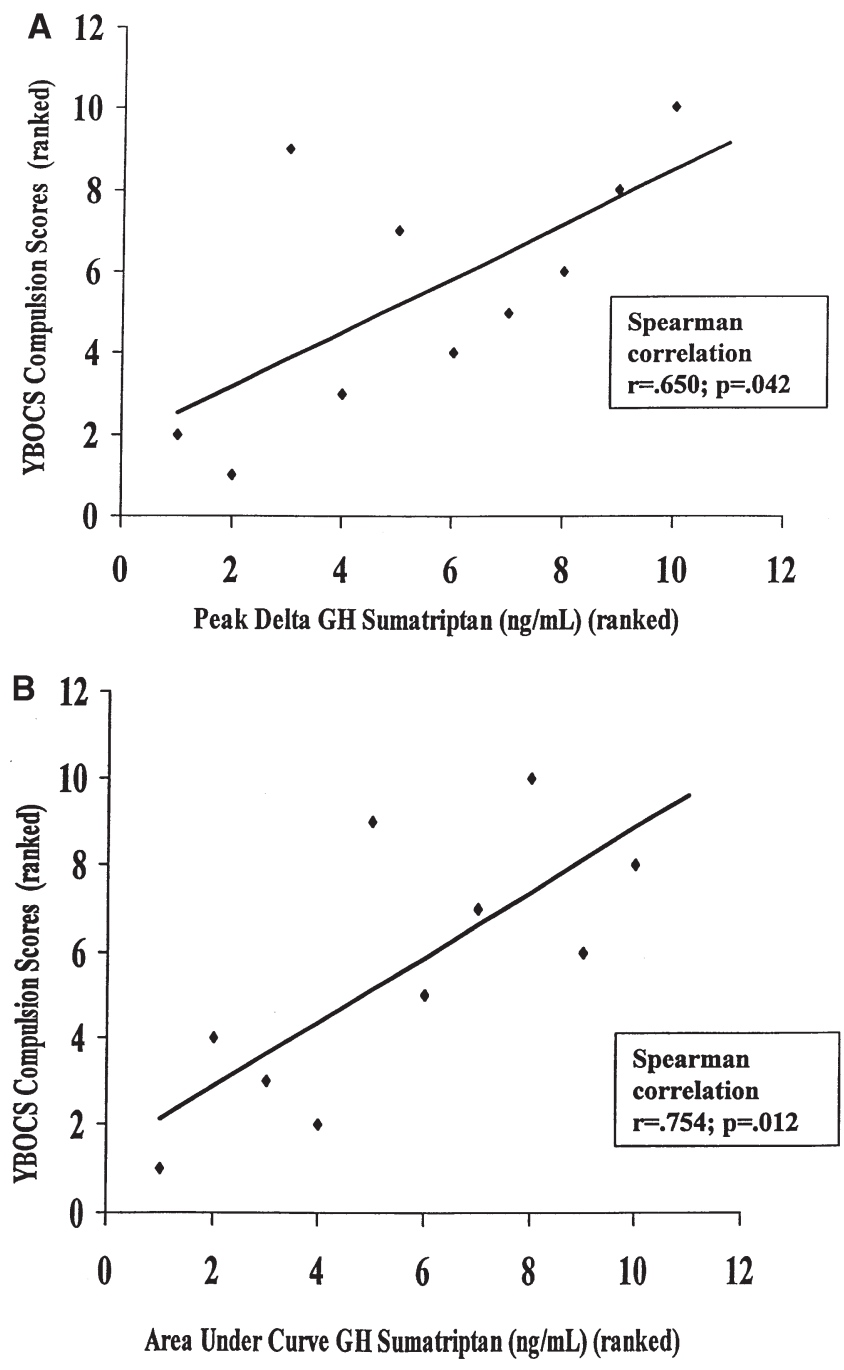

Figure 1. Relationship between 5HT 1d receptor sensitivity and repetitive behaviors in autistic patients (sumatriptin).

related to non-specific stressors such as IV insertion. In a parallel study under identical conditions, we found that growth hormone response to sumatriptan in 11 patients with autism was greater than for matched nine normal controls. In controls, peak delta GH response to sumatriptan was $2.27 \pm 2.20$ vs. $1.84 \pm 2.76$ for placebo, and area under the curve GH response was $14.56 \pm 14.80$ sumatriptan vs. $11.90 \pm 18.85$ with placebo. These values were compared to autism patients by t-test and were found to differ at the $p \leq .10$ level (Novotny et al. 1999 in press). This is consistent with hypersensitivity of the $5 \mathrm{HT} 1 \mathrm{~d}$ receptor in autism.

GH response to sumatriptan in healthy individuals may be mediated by 5 -HT1d receptors located in the median eminence of the hypothalamus which facilitate the release of growth hormone releasing hormone (GHRH) which in turn stimulates GH release (Franceschini et al. 1994; Yatham et al. 1997). Stimulation of 5HT 1d receptors may also inhibit the release of somatosta- 
tin thereby decreasing inhibitory tone on $\mathrm{GH}$ release (Mota et al. 1995).

The findings of this study must be viewed with caution given the small number of patients studied; the inability to extrapolate these findings to females (since ten of the eleven patients who participated in this study were males) and to children and adolescents (since the study was restricted to adults), and difficulty in delineating the relationship between repetitive behaviors and GH response separately for Asperger's vs. autism patients (given the small sample size). Future studies are needed to replicate these findings with larger sample sizes, to determine whether this relationship between 5HT function and repetitive behavior occurs in both Asperger's disorder and autism patients, and to examine findings in females, children, and adolescents. Also, these findings need to be integrated with simultaneous measurement of other 5-HT indices, such as whole blood 5-HT. Finally, this relationship should also be studied in patients with other disorders characterized by repetitive behaviors, such as obsessive compulsive disorder.

Nevertheless, these findings are clinically relevant in helping to sort out heterogeneity in autism by linking a specific neurobiological marker (5HT 1d function) to a specific behavioral symptom dimension (repetitive behaviors). Future studies are needed to address whether this finding is of relevance to treatment response to selective serotonin reuptake inhibitors in autism.

\section{ACKNOWLEDGMENTS}

Supported in part by the Seaver Foundation, a grant from Glaxo Wellcome Pharmaceuticals, and by grant $5 \mathrm{MO} 1$ RR00071 for the Mount Sinai General Clinical Research Center from the National Center for Research Resources, National Institutes of Health.

\section{REFERENCES}

Adham N, Bard JA, Zgombick JM, Durkin MM, Kucharewicz S, Weinshank RL, Branchek TA (1997): Cloning and characterization of the guinea pig 5HT 1f receptor subtype: A comparison of the pharmacological profile to the human species homolog. Neuropsychopharmacology 36:569-576

Anderson GM, Freedman DX, Cohen DS, Volkmar FR, Hoder EL, McPhederan P, Minderaa RB, Hansen CR, Young JG (1987): Whole blood serotonin in autistic and normal subjects. J Child Psychol Psychiatry 28:885-900

Bard JA, Kucharewicz SA, Zgombik JM, Weinshank RL, Branchek TA, Cohen ML (1996): Differences in ligand binding profiles between cloned rabbit and human 5HT 1d alpha and 5HT 1d beta receptors: Kentanserin and methiothepin distinguish rabbit 5HT $1 \mathrm{~d}$ receptor subtypes. Naunyn Schmeidebergs Arch Pharmacol 354:237-244

Bolton PF, Pickles A, Murphy M, Rutter M (1998): Autism, affective and other psychiatric disorders: Patterns of familial aggregation. Psychol Med 28:385-395

Cook EH, Charak DA, Arida J, Spohn JA, Roizen NJM, Leventhal BL (1994): Depressive and obsessive-compulsive symptoms in hyperserotonemic parents of children with autistic disorder. Psychiatric Res 52:25-33

Cook EH, Courchesne R, Lord C, Cox NJ, Yan S, Lincoln A, Haas R, Courchesne E, Leventhal BL (1997): Evidence of linkage between the serotonin transporter and autistic disorder. Mol Psychiatry 2:247-250

Chugani DC, Muzik O, Rothermel R, Behen M, Chakraborty P, Mangner T, da Silva EA, Chugani HT (1997): Altered serotonin synthesis in the dentatothalamocortical pathway in autistic boys. Ann Neurol 42:666-669

Franceschini R, Cataldi A, Garibaldi P, Cianciosi P, Scordamaglia A, Barreca T, Rolandi E (1994): The effects of sumatriptan on pituitary secretion in man. Neuropharmacology 33:235-239

Gordon CT, State RC, Nelson JE, Hamburger SD, Rapoport JL (1993): A double-blind comparison of clomipramine, desipramine, and placebo in the treatment of autistic disorder. Arch Gen Psychiatry 50:441-447

Hollander E, Cartwright C, Wong CM, DeCaria CM, DelGiudice-Asch G, Buchsbaum MS, Aronowitz B (1998): A dimensional approach to the autism spectrum. CNS Spectrums: Intl J Neuropsych Med 3:22-39

Hollander E, DelGiudice-Asch G, Simon L, Schmeidler J, Cartwright C, DeCaria C, Kwon J, Cunningham-Rundles C, Chapman F, Zabriskie J (1999): B-lymphocyte antigen D8/17 and repetitive behaviors in autism. Am J Psychiatry 156:317-320

Hoshino Y, Yamamoto T, Kaneko M, Tachibana R, Watanabe M, Ono Y, Kumashiro H (1984): Blood serotonin and free tryptophan concentration in autistic children. Neuropsychobiology 11:22-27

Klauck SM, Poustka F, Brenner A, Lesch KP, Poustka A (1997): Serotonin transporter (5HTT) gene variants associated with autism? Human Mol Genet 6(13):2233-2238

Leboyer M, Philippe A, Bouvard M, Guilloud-Bataille M, Bondoux D, Tabuteau F, Feingold J, Mouren-Simeoni, MC, Launay JM (1999): Whole blood serotonin and plasma beta-endorphin in autistic probands and their first degree relatives. Biol Psychiatry 45:158-163

Lord C, Rutter M, LeCouteur A (1994): Autism Diagnostic Interview-Revised: A revised version of a diagnostic scale for caregivers of individuals with possible pervasive developmental disorders. J Autistic Devel Dis 24(5): 659-685

McBride PA, Anderson GM, Hertzig ME, Sweeny JA, Kream J, Cohen DJ, Mann JJ (1989): Serotonergic responsivity in male young adults with autistic disorder. Results of a pilot study. Arch Gen Psychiatry 46:213-221

McDougle CJ, Naylor ST, Cohen DJ, Aghajanian GK, Henninger GR, Price LH (1996a): Effects of tryptophan depletion in drug-free adults with autistic disorder. Arch Gen Psychiatry 53:993-1000

McDougle CJ, Naylor ST, Cohen DJ, Volkmar FR, Heninger GR, Price LH (1996b): A double-blind, placebo con- 
trolled study of fluvoxamine in adults with autistic disorder. Arch Gen Psychiatry 53:1001-1008

Mehlinger R, Scheftner WA, Pozanski E (1990): Fluoxetine and autism. J Am Acad Child Adolesc Psychiatry 29:985

Mota A, Bento A, Peñalva A, Pombo M, Dieguez C (1995): Role of serotonin receptor subtype 5-HT 1d on basal and stimulated growth hormone secretion. J Clin Endocrinol Metab 80:1973-1977

Novotny S, Hollander E, Allen A, Mosovich S, Aronowitz B, Cartwright C, DeCaria C (1999): Increased growth hormone response to sumatriptan challenge in adult autistic disorders. Psychiatric Res, in press

Pascual J, del Arco C, Romon T, del Olmo E, Castro E, Pazos A (1996): Autoradiographic distribution of [3H] sumatriptan-binding sites in post-mortem human brain. Cephalalagia 16(5):317-322
Peroutka SJ, McCarthy BG (1989): Sumatriptan (GR 43175) interacts selectively with 5-HT1B and 5-HT1D binding sites. Eur J Pharmacol 163:133-136

Piven J, Tsai G, Nenme E, Coyle JT, Folstein SE (1991): Platelet serotonin, a possible marker for familial autism. J Autism Der Disord 21:51-59

Steingard RJ, Ziminitzky B, DeMaso DR, Bauman ML, Bucci JP (1997): Sertraline treatment of transition-associated anxiety and agitation in children with autistic disorder. J Am Acad Child Adolesc Psychiatry 7:9-15

Yatham LN, Lam RW, Zis AP (1997): Growth hormone response to sumatriptan (5-HT1d agonist) challenge in seasonal affective disorder: Effects of light therapy. Biol Psychiatry 42:24-29 